\title{
Mechanical Properties of Natural Rubber Composites Filled with Starch Sludge Compared with Other Waste and Commercial Fillers
}

\author{
Duangkamol Dechojarassri, Narumon Ratikant, Siriphat Charoenrat, and Panu Danwanichakul
}

\begin{abstract}
Mechanical properties of natural rubber composites filled with waste materials including waste tire rubber, rice husk ash and starch sludge were comparatively investigated along with commercial reinforcing fillers, carbon black and silica, using maleated natural rubber (MNR) or silane (Si69) as a coupling agent. It was found that rubber with rice husk ash gave higher tensile strength than ones with starch sludge and waste tire. Rice husk ash gave similar strength to silica and using MNR was better than Si69. Waste fillers gave higher compression set than carbon black and crumb rubber yielded better abrasive resistance than carbon black and silica. It was also seen that mechanical properties decreased with increasing starch sludge loading. The optimum loading is $10 \mathrm{phr}$ starch sludge with $5 \mathrm{phr}$ MNR. These experimental results showed that for certain applications, waste materials could be used as alternative filler in the rubber production.
\end{abstract}

Index Terms-Rice husk, rubber composite, starch sludge, waste tire.

\section{INTRODUCTION}

Thailand is one of top three natural rubber producers in the world but the rubber usage in the country is less than what expected by the government because it is more expensive than synthetic rubber. To promote an increase in usage of domestic natural rubber could, therefore, help stabilize the rubber cost in the market. One of the promising methods to reduce the production cost nowadays is using low-cost fillers together with a cheap vulcanizing system. On one hand, carbon black and silica are widely used as commercial reinforcing fillers for the production of natural rubber products and some other polymers. On the other hand, calcium carbonate is considered as inexpensive filler to increase volume of the final rubber products and thereby reducing the cost of production. Low-cost fillers possessing the reinforcing properties would be interesting choices for rubber production in this aspect.

Manuscript received December 19, 2016; revised May 5, 2017.

D. Dechojarassri, N. Ratikant, S. Charoenrat are with the Department of Chemical Engineering, Faculty of Engineering, Thammasat University, Thailand. Currently, D. Dechojarassri is with the Faculty of Chemistry, Materials and Bioengineering, Kansai University, Osaka, 564-8680, Japan (e-mail: Duangkamold@hotmail.com)

D. Danwanichakul is with the Department of Chemical Engineering, Faculty of Engineering, Thammasat University, Klong-Nung, Klong-Luang, Pathumthani, 12120, Thailand (dpanu@engr.tu.ac.th).
The idea of using waste materials as fillers in rubber composites has been attracting many researchers for a very long time. For example, eggshell in micron sized particles together with carbon black was added to increase mechanical strength of the composites [1]. As a method to get rid of waste tire rubber, it was made into small granules and added as filler in the new rubber compound [2]. Agricultural waste also gained much attention, for instance, lignin [3] or softwood-lignin [4], short pineapple leaf fibers [5] and rice husk ash (RHA) [6] were added as fillers into the rubber composites. In addition, plastic wastes were also blended to rubber compound such as ethylene-vinyl acetate (EVA) [7] and waste poly amide [8].

As studied in the old systems of commercial fillers, the interaction among filler particles and rubber matrix is always the main concern in the mixing process since natural rubber is highly hydrophobic. Addition of hydrophilic particles such as silica is expected to yield poor mixing with rubber. To solve the problem of immiscibility between these materials, a compatibilizing agent or coupling agent is needed. One of the common coupling agent is a group of silane coupling agent. However, grafting rubber molecules with maleic anhydride to increase polarity in rubber molecules and using the grafted-rubber as a coupling agent proved to increase compatibility among rubber and paper sludge [9]. Therefore, maleated natural rubber (MNR) [10] could be a promising coupling.

However, each research work used different formulation in the mixing process so it was difficult to compare the efficiency of those wastes as filler in the rubber composites. In order to compare the efficiency of some wastes as filler, they need to be investigated in the same vulcanizing system, i.e. same rubber formulation during the mixing process. This research focuses on a study of using waste materials including waste tire rubber (waste tire granules), rice husk ash (RHA) from a rice mill and starch sludge from a modified-starch factory. These materials are composed of carbon and/or silica which should enhance the mechanical properties of natural rubber composites so they were later called alternative filler throughout the text. Furthermore, this could increase the value of these waste materials and starch sludge. The objectives of this study are to compare the mechanical properties of rubber filled with different alternative fillers with those of commercial fillers and without or with some amount of MNR or Si69 as a coupling agent which boost compatibility between filler and rubber matrix and also to evaluate the effect of starch sludge loading with different amount of MNR and Si69 on mechanical properties. 


\section{EXPERIMENTAL PROCEDURE}

\section{A. Materials}

STR 5L grade natural rubber was supplied by Rubber Estate Organization. Silica, stearic acid, and zinc oxide were provided by Loxley Co., Ltd. Waste tire granules or crumb rubber (7, 10 and 30 mesh) was bought from Union Pattanakit Co., Ltd, Starch sludge was obtained from Siam modified starch Co.,Ltd while rice husk ash (RHA) was provided from Pathum Rice Mill Co., Ltd. Tetramethylthiuram disulfide (TMTD) and Si-69 (bis-( 3-triethoxysilylpropyl)tetrasulfane) was given by JJ-Degussa Chemicals Ltd. N-Cyclohexyl-2-benzothiazole sulfonamide (CBS) by Sunny World (1989) Co. Ltd. Carbon Black (N330) was purchased from Loxley Co., Ltd and sulfur was purchased from Suksaphan Panich.

\section{B. Fillers Preparation}

Starch sludge was dried in an oven at $100^{\circ} \mathrm{C}$ for $20 \mathrm{~h}$ and then ground with a ball-mill to a powder form. The particles were then sieved to separate particles less than 75 micrometer from those larger than 75 micrometer. The same method was done for rice husk ash.

\section{Preparation of Maleated Natural Rubber (MNR) as a Coupling Agent}

Maleated Natural Rubber was prepared by blending natural rubber with $5 \mathrm{phr}$ of maleic anhydride in an internal mixer, Brabender. The natural rubber was first dried in an oven at $40^{\circ} \mathrm{C}$ for $24 \mathrm{~h}$. The internal mixer was then used to masticate the rubber at $135^{\circ} \mathrm{C}$ with a rotor speed of $60 \mathrm{rpm}$. The mixing was continued for $8 \mathrm{~min}$.

\section{Mixing Procedure}

Typical rubber formulation used in this research is provided in Table I.

TABLE I: RUBBER COMPOSITE FORMULATION

\begin{tabular}{cc}
\hline \hline Materials & Composition $\left(\mathrm{phr}^{*}\right)$ \\
\hline STR 5L & 100 \\
Stearic acid & 1 \\
Zinc Oxide & 5 \\
CBS & 0.5 \\
TMTD & 0.1 \\
Fillers & 30 \\
Si-69** & 2.4 \\
Sulfur & 2.5 \\
\hline \hline
\end{tabular}

phr stands for parts per hundred parts of rubber

${ }^{* * *}$ Used only with rubber filled with RHA and silica

Mixing was carried out in the Brabender at $50^{\circ} \mathrm{C}$ with a rotor speed at $40 \mathrm{rpm}$. Mixing was a two-staged process. At the first stage, rubber was masticated for $3 \mathrm{~min}$ and then mixed with fillers for 2-4 min depending on the type of fillers. Subsequently, stearic acid and zinc oxide were filled and mixed together for $3 \mathrm{~min}$ and then the rubber was rolled with a two-roll mill and cut for the next stage. At the second stage, the rubber from the first stage was mixed with CBS, TMTD and sulfur at $55^{\circ} \mathrm{C}$ for $2 \mathrm{~min}$, rolled with the two-roll mill and a piece of rubber was cut for testing the cure characteristics at Rubber Research Institute (Thailand). Finally, the rubber was molded in different shapes appropriate for different mechanical property test.

Stearic acid and zinc oxide were used as activators. CBS and TMTD were used as accelerators. The fillers used were carbon black (CB), silica (Si), crumb rubber of size 7 mesh $(2.8 \mathrm{~mm})(\mathrm{CR} 7 \mathrm{M}), 10 \mathrm{mesh}(1.65 \mathrm{~mm})(\mathrm{CR} 10 \mathrm{M})$, and 30 mesh $(0.54 \mathrm{~mm})(\mathrm{CR} 30 \mathrm{M})$, rice husk ash of mixed sizes (RHA), rice husk ash of mixed sizes with Si69 (RHA+Si69), rice husk ash of mixed sizes with MNR (RHA+MNR), rice husk ash of size less than 75 microns (RHA $<75)$, rice husk ash with size less than 75 microns with Si-69 (RHA<75+Si69), rice husk ash with size less than 75 microns with MNR (RHA<75+MNR), starch sludge (SS), starch sludge with Si69 (SS+Si69), and starch sludge with MNR (SS+MNR).

\section{E. Mechanical Properties Testing Surface Hardness}

Samples were tested with dead load hardness tester, shore A, at room temperature according to ASTM D 2240.

\section{1) Tensile strength}

According to ASTM D412, dumb-bell shaped samples were cut from the molded sheets, die C, which is $25 \mathrm{~mm}$ of gauge length and tested by using the universal testing machine (UTM). The test sample looks as shown in Fig. 1.

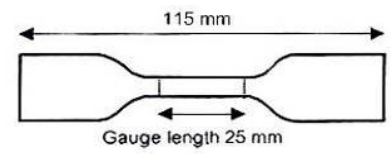

Fig. 1. Dumb-bell shaped sample.

\section{2) Compression set}

Cylinder shaped samples were cut, with $1.25 \mathrm{~cm}$ thickness and $3 \mathrm{~cm}$ diameter as shown in Fig. 2.

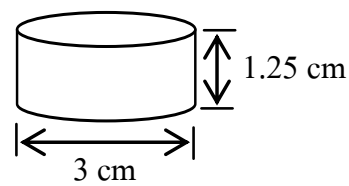

Fig. 2. Compression-set samples.

According to ASTM D 395-89, the sample was put between metal sheets of tester. The compression tester had spacer bars for setting a distance of compression. The sample was compressed so that the thickness decreased about $25 \%$ from the origin and then the tester along with the sample was aged in an oven at $100{ }^{\circ} \mathrm{C}$ for $22 \mathrm{~h}$. The sample was later taken out of the tester and held at room temperature. The thickness of the sample was measured and \%compression set can be calculated according to Eq. (1).

$$
\% C_{B}=\left[\left(t_{0}-t_{1}\right) /\left(t_{0}-t_{\mathrm{n}}\right)\right] \times 100
$$

Here, $\% C_{B}$ is the percentage of compression set, $t_{0}$ is the thickness of the sample before aging $(\mathrm{mm}), t_{1}$ is the thickness of the sample after aging $(\mathrm{mm})$ and $t_{n}$ is the thickness of space bars (mm).

\section{3) Abrasion resistance}

Samples were cut in cylindrical shape with its length and diameter of 2.5 and $1.2 \mathrm{~cm}$, respectively. Testing method is according to DIN 53516. The volume losses $\left(\mathrm{mm}^{3}\right)$ could be calculated by using Eq. (2). 
Volume loss $=\Delta m \times S_{0} /($ density $\times S)$

where, $\Delta m$ is weight loss, $S_{0}$ is abrasion power. In this case $S_{0} / S$ was set to $10 / 9$.

\section{4) Scanning electron microscopy (SEM)}

The samples were cracked in liquid nitrogen. The cracked surface was examined by SEM (Jeol JSM 6301F) at MTEC.

\section{RESUlTS AND DISCUSSION}

To clarify the effect of fillers on mechanical properties of the rubber composites, one may follow previous research works and compare the results. However, it is very difficult to do so since each research work applied different formulation of the effective chemicals including vulcanizing agents and fillers, thereby yielding different vulcanizing systems. The mechanical properties of rubber composites are dependent on the degree of vulcanization which may be considered as a chemical crosslink and the type of vulcanizing system as well as the degree of physical crosslink between rubber molecules and filler particles. Therefore, to compare the effect of fillers, the effect of vulcanizing systems should be avoided. To that end, in this work all experiments using waste fillers and commercial adopted the same rubber formulation as shown in Table I.

\section{A. Tensile Properties}

The universal testing machine was used to obtain tensile properties including tensile strength, the maximum tensile stress the rubber sample can withstand before being drawn to break, and elongation at break showing the elasticity of the sample through the maximum length of the sample being breaking.

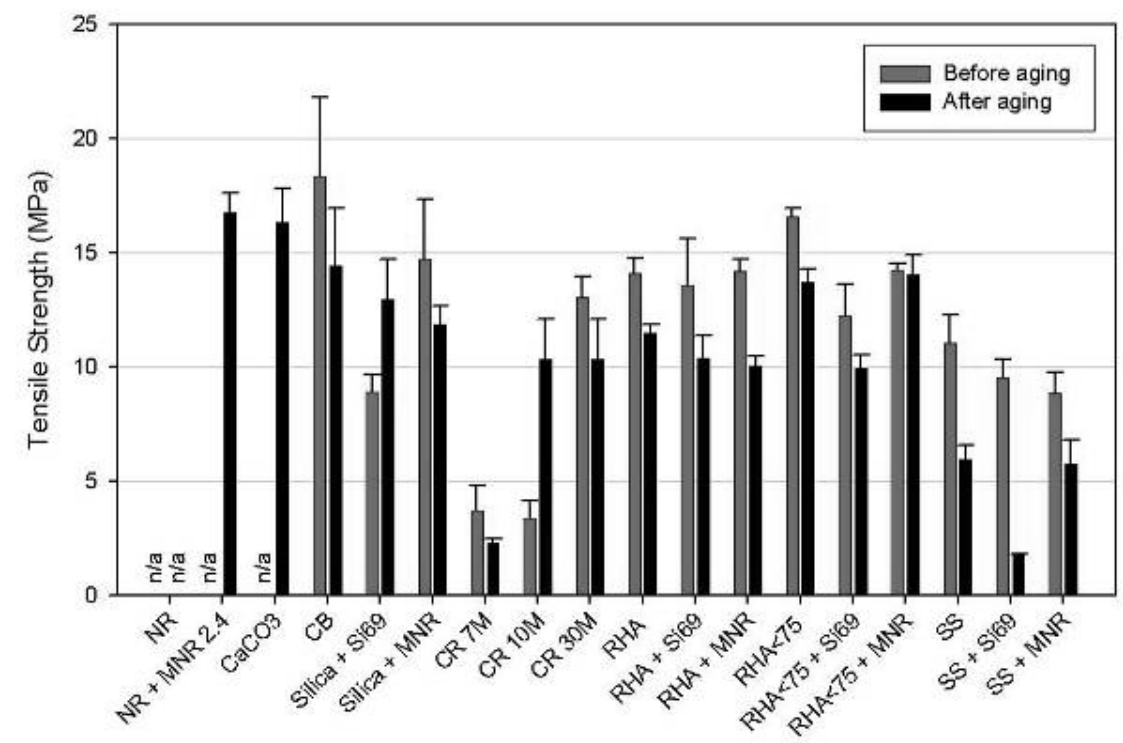

Fig. 3. The effect of various fillers on tensile strength.
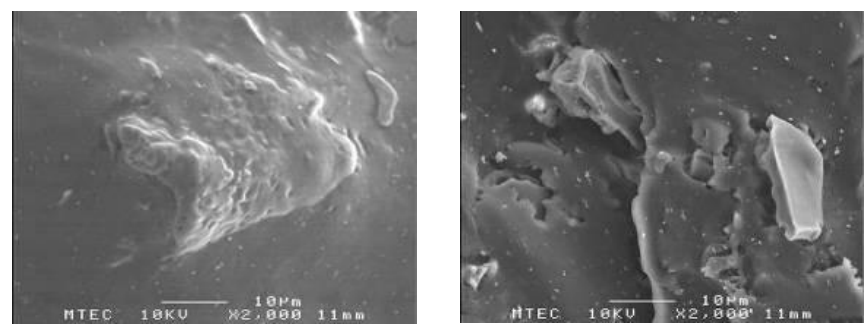

Fig. 4. SEM micrograph of rubber filled with (a) RHA $<75+$ MNR 2.4 phr or (b) RHA<75 + Si69 2.4phr.

Fig. 3 shows the comparison between each rubber filled with various fillers. It was found that the rubber filled with carbon black has a highest tensile strength at $18 \mathrm{MPa}$. Rubber filled with rice husk ash has tensile strength close to that filled with silica, but greater than rubber filled with starch sludge and crumb rubber, respectively. However, it should be noted that the smallest size of crumb rubber (CR 30M) yielded high tensile strength comparable to rice husk ash. The small size of filler is one of important factors in strengthening the interaction between rubber and filler. As the size decreases, the area per unit volume of the particle increases resulting in strong attractive interactions among particles and rubber molecules. As can be seen also from Fig. 3, rice husk ash with smaller size gave better tensile strength.

Considering the use of coupling agents, it was unexpectedly seen that rubber without coupling agent was better than that with coupling agent, likely attributable to poor mixing process. However, MNR seemed to be a better coupling agent than Si69.

Fig. 4 shows that the compatibility between rubber-filler was improved by using MNR. The particles were better mixed into the rubber matrix because they could be more effectively distributed in the matrix, not aggregated into larger particles.

Fig. 5 shows the effect of starch sludge loading in rubber. It was obviously seen that tensile strength decreased with increasing starch sludge loading both in the case of using and 
not using NMR. As the amount of filler was increased, the filler particles or aggregates were no longer separated or wetted by rubber matrix. So the reduction in tensile strength might be due to the agglomeration of filler particles [6].

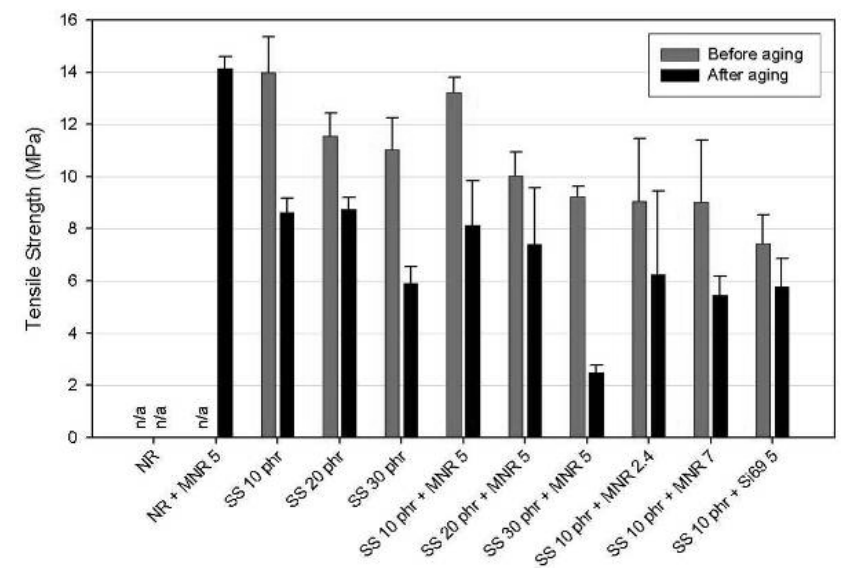

Fig. 5. The effect of starch sludge loading on tensile strength.

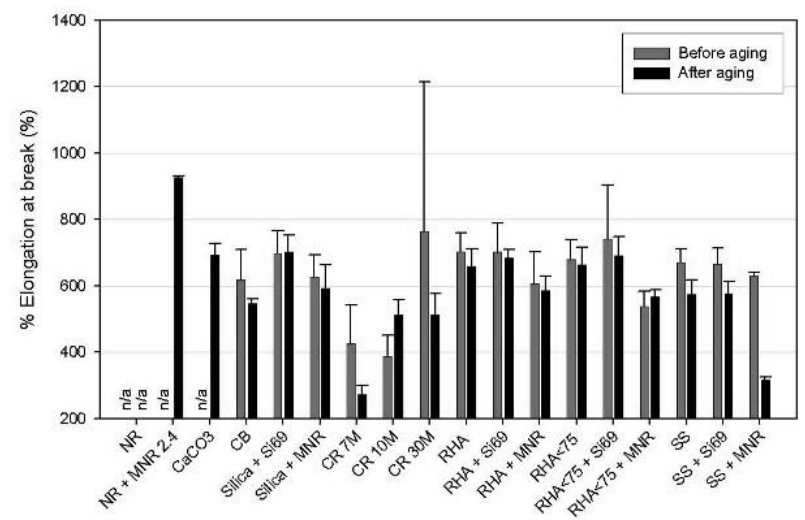

Fig. 6. The effect of various filler on \%elongation.

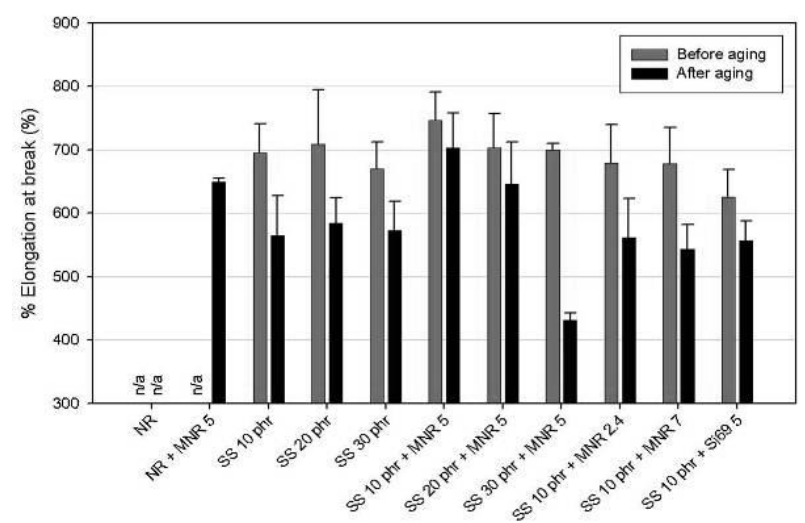

Fig. 7. The effect of filler loading on \%elongation.

Elongation at break reflecting the elastic property of rubber vulcanizates is shown in Fig 6. It was found that the rubber filled with carbon black elongated at break point less than that with silica. The rubber filled with rice husk ash again showed elongation at break close to that with silica, and greater than those with starch sludge and crumb rubber. Similarly, crumb rubber of the smallest size (CR 30M) gave very good elongation at break which is nearly $700 \%$.

Fig. 7 shows the elongation at break for rubber filled with different starch sludge loading. It can be seen that MNR could improve elastic properties of rubber and with increasing loading the elastic properties seemed to decrease. The optimum formula was rubber filled with $10 \mathrm{phr}$ of starch sludge and $5 \mathrm{phr}$ of MNR which gave the highest elongation.

\section{B. Surface Hardness}

The surface hardness of the rubber filled with commercial fillers was 38-42 shore A, whereas for those filled with crumb rubber it was 38-45 shore $\mathrm{A}$ and for those filled with rice husk ash and starch sludge it was in the range of 40-50 shore A. In addition, the surface hardness decreased with increasing starch sludge loading.

\section{Compression Sets}

Higher percentage of compression set represents lower resilient properties. The compression set of rubber filled with commercial fillers was $40 \%$. For alternative filler, percent of compression set was in the range of 40-50\%. The rubber-filler composite with MNR as coupling agent yielded less compression set than rubber-filler composite coupled with Si69.

\section{Abrasion Resistance}

The volume loss was obtained during abrasion test. More loss represents less abrasion resistance. It was noted that the rubber filled with crumb rubber had $20-35 \mathrm{~mm}^{3}$ of volume loss, lower than those of rubber filled with commercial filler and unfilled rubber, showing a promising application that needs abrasion resistance.

\section{CONCLUSION}

The mechanical properties of natural rubber composites filled with waste materials and starch sludge compared with commercial fillers were investigated. The results showed that rice husk ash seemed to be the promising alternative filler to silica and that starch sludge and crumb rubber had adequate mechanical properties for certain appropriate applications, provided that the particle sizes are very small. The rubber filled with waste materials could improve compression set of rubber compound, better than the commercial silica but still lower than carbon black. The weight losses of rubber composites filled with waste tire particles during abrasion tests were the least among all samples especially when compared with silica. With suitable applications, waste materials could be used as inexpensive filler in the rubber products.

\section{ACKNOWLEDGMENT}

We are grateful to The Cleaner Technology Internship Program, Thammasat University Node for funding and to the Department of Chemical Engineering and the Department of Industrial Engineering, Faculty of Engineering, Thammasat University for essential equipment. We also appreciate assistances from Rubber Research Institute (Department of Agriculture), Rubber Estate Organization, Siam Modified Starch Co., Ltd, Pathum Rice Mill Co., Ltd, and Loxley Co., Ltd.

\section{REFERENCES}

[1] C. S. Barrera and K. Cornish, "High performance waste-derived filler/carbon black reinforced grayule natural rubber composites," Industrial Crops and Products, vol. 86, pp. 132-142, Aug. 2016. 
[2] S. Ramarad, M Khalid, C. T. Ratnam, A. L. Chuah, and W. Rashmi, "Waste tire rubber in polymer blends: A review on the evolution, properties and future," Progress in Materials Science, vol. 72, pp. 100-140, Jul. 2015.

[3] P. Yu, H. He, Y. Jia, S. Tian, J. Chen, and D. Jia, "A comprehensive study on lignin as a green alternative of silica in natural rubber composites," Polymer Testing, vol. 54, pp. 176-185, Sep. 2016.

[4] J. Datta, P. Parcheta, and J. Surowka, "Softwood-lignin/natural rubber composites containing novel plasticizing agent: Preparation and characterization," Industrial Crops and Products, vol. 95, pp. 675-685, Jan. 2017.

[5] K. Yantaboot and T. Amonsakchai, "Effect of mastication time on the low strain properties of short pineapple leaf fiber reinforced natural rubber composites," Polymer Testing, vol. 57, pp. 31-37, Feb. 2017.

[6] H. Ismail, M. Nasaruddin, and U. S. Ishiaku, "White rice husk ash filled natural rubber compounds: the effect of multifunctional additive and silane coupling agents," Polymer Testing, vol. 18, pp. 287-298, Jun. 1999.

[7] D. Lopes, M. J. Ferreira, R. Russo, and J. M. Dias, "Natural and synthetic rubber/waste - Ethylene-Vinyl Acetate composites for sustainable application in the footwear industry," Journal of Cleaner Production, vol. 92, pp. 230-236, Apr. 2015.

[8] M. M. Hassen, "Synergistic effect of montmorillonite-clay and gamma radiation on the characterizations of waste polyamide copolymer and reclaimed rubber powder nanocomposites," Composites Part B: Engineering, vol. 79, pp. 28-34, Sep. 2015.

[9] H. Ismail, A. Rusli and A. A. Rashid, "Maleated natural rubber as a coupling agent for paper sludge filled natural rubber composites," Polymer Testing, vol. 24, pp. 856-862, Oct. 2005.

[10] C. Nakason, A. Kaesaman, and P. Supasanthitikul, "The grafting of maleic anhydride onto natural rubber" Polymer Testing, vol. 23, pp. 35-41, Feb. 2004.

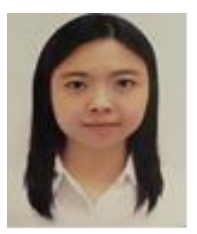

Duangkamol Dechojarassri received her bachelor degree in chemical engineering from Thammasat University, Rangsit Campus, Pathumthani, Thailand in 2003 and continued her master thesis in chemical engineering at the same university with the topic of "Mechanical Properties Enhancement of Wood-like Natural Rubber Composite" and finished master degree in 2005. She is now pursuing her Ph.D. at Faculty of Chemistry, Materials and Bio- engineering, Kansai University, Osaka, Japan.

After she got her master degree in chemical engineering, she had worked as a research assistant in a material laboratory of the department of chemical engineering, Thammasat University. During that time, she coauthored many

articles, most of which were about investigations of natural rubber in various aspects and its applications.

Her master thesis was of so much interest that Miss Dechojarassri received best thesis award from Thammasat University. In addition, during her master study, she was financially supported by the scholarship from Royal Thai Government (RTG).

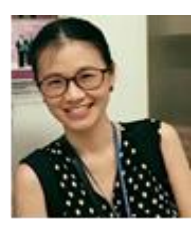

Thailand.

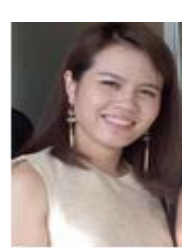

Siriphat Charoenrat received her bachelor degree in chemical engineering from Thammasat University, Rangsit Campus, Pathumthani, Thailand in 2009 and received her master degree in management from College of Manangement, Mahidol University, Thailand. She is now working at SCG company, Thailand.

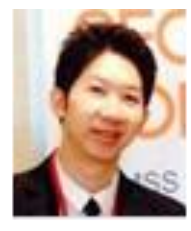

He is now working as an associate professor in the Department of Chemical Engineering, Faculty of Engineering, Thammasat University. His research interests are in the filed of natural rubber technology and material sciences, especially on nanomaterials and their applications. He is also interested in molecular simulation and statistical thermodynamics as it is the background of his Ph.D. thesis.

Assoc. Professor Danwanichakul received the best thesis award from National Research Council of Thailand and received best research award from Thammasat University and various sources of research funding. 